\title{
Association of Urinary Prostaglandin E2 Metabolite and Mortality among Adults
}

Wanqing Wen ( $\nabla$ wanqing.wen@vumc.org )

Vanderbilt University Medical Center https://orcid.org/0000-0002-3004-5168

\section{Gong Yang}

Vanderbilt University Medical Center

\section{Qiuyin Cai}

Vanderbilt University Medical Center

Xiao-ou Shu

Vanderbilt University Medical Center

Wei Zheng

Vanderbilt University Medical Center

\section{Research}

Keywords: prostaglandin, inflammation, lifestyle, mortality, survival

Posted Date: February 16th, 2021

DOI: https://doi.org/10.21203/rs.3.rs-195622/v1

License: (c) (i) This work is licensed under a Creative Commons Attribution 4.0 International License. Read Full License 


\section{Abstract \\ Background}

Prostaglandins play a critical role in inflammatory response. It has become widely accepted that chronic inflammation is a driving force behind many chronic diseases, such as cancers and cardiovascular diseases, the major causes of death in the world today. The studies on the association between biomarkers of inflammation and mortality are limited.

\section{Methods}

To investigate the association of urinary PGE-M, a stable end-product of prostaglandin E2 ( $\left.\mathrm{PGE}_{2}\right)$ with overall and cause-specific mortality and examine potential effect modifiers, we obtained urinary PGE-M levels of 2,927 noncancerous adults from our previous case-control studies nested in the Shanghai Women's Health Study and Shanghai Men's Health Study, two cohort studies conducted in Shanghai, China. We collected mortality data and modifiable factors associated with urinary PGE-M were obtained from the parent cohort studies.

\section{Results}

Using linear regression models, we found that high urinary PGE-M levels were significantly associated with low education, heaving smoking, old age at urine collection, and abdominal obesity. Using Cox proportional hazards models, we found that increase (per standard deviation) of urinary PGE-M levels were significantly associated with overall mortality (adjusted hazard ratio $=1.19,95 \%$ confidence interval: $1.07,1.33$ ) and particularly deaths from cardiometabolic diseases (adjusted hazard ratio $=1.27,95 \%$ confidence interval: 1.11, 1.44). The increased death risks persisted across different time intervals during the follow-up and were stronger among participants who were younger than 60 ( $P=0.0014$ for all- cause mortality and $P=0.007$ for deaths from cardiometabolic diseases) at urine collection or perhaps among those who had higher education.

\section{Conclusions}

High urinary PGE-M levels were associated with a significantly increased risk of all causes of death and particularly deaths from cardiometabolic diseases. Improving lifestyles, e.g., stopping smoking and controlling body weight, would help decrease mortality through decreasing over-production of $\mathrm{PGE}_{2}$.

\section{Background}

Prostaglandins (PGs) play a critical role in the generation of the inflammatory response (1). PGE 2 is one of the most abundant PGs produced in the body and is involved in all processes leading to the classic signs of inflammation. This metabolite is an important mediator of many biological functions, such as regulation of immune responses, blood pressure, gastrointestinal integrity, and fertility.

$\mathrm{PGE}_{2}$ is an unstable compound that is rapidly metabolized in vivo to a stable metabolite, 11 a-hydroxy-9,15-dioxo2,3,4,5-tetranorprostane-1,20-dioic acid (PGE-M). Thus, measurement of excreted urinary PGE-M has been used to 
quantify systemic $\mathrm{PGE}_{2}$ production in vivo. Urinary level of PGE-M is considered to have a more complete capture

of prostaglandin production, as it will reflect a combination of prostaglandins from both the blood stream and the kidney $(2,3)$. We have previously reported the association between urinary PGE-M levels and multiple cancer risks.

In addition to cancers, it has become widely accepted that chronic inflammation is a driving force behind many other chronic diseases(1,4-6), including ischemic heart disease, stroke, and diabetes mellitus, which are the major causes of death in the world today(7). Over the past decade, we have conducted multiple nested case-control studies (8-13) to investigate the association between urinary PGE-M levels and multiple cancer risks and found the individuals with higher urinary PGE-M levels had increased risks of colorectal cancer (8), gastric cancer(12), breast cancer(10), and pancreatic cancer(11).

In addition, the detrimental effects of chronic inflammation on health are now known to persist throughout the life span to increase adulthood mortality. Characterizing the association of chronic inflammation with health risk and life span should thus also be a top public health priority. To this end, we investigated the modifiable factors associated with urinary PGE-M levels and test whether the latter were associated with premature death in this study.

\section{Methods}

\section{Study population}

The 2,927 non-cancerous adults included in this study consisted of controls from our previously case-control studies nested in the Shanghai Women's Health Study (SWHS) and Shanghai Men's Health Study (SMHS), two ongoing prospective cohort studies conducted in Shanghai, China. Mortality data and modifiable factors associated with urinary PGE-M were obtained from the parent cohort studies. The parent studies were approved by the institutional review boards of all participating institutions. Detailed descriptions of study design and methods have been published elsewhere(14,15). Briefly, participants were recruited from typical urban communities in Shanghai, China. The SWHS recruited 74,941 women aged 40-70 years from 1996 to 2000 with a $92.7 \%$ participation rate in the baseline survey. The SMHS recruited 61,480 men aged 40-74 years from 2002 to 2006 with a $74.0 \%$ participation rate in the baseline survey. At the time of enrollment, each participant signed consent and completed an in-person survey conducted by trained interviewers. Of the study participants, 65,754 (88\%) women and 54,769 (89\%) men provided a spot urine sample. Urine samples were collected into a sterilized cup containing $125 \mathrm{mg}$ ascorbic acid to prevent oxidation of labile metabolites. After collection, the samples were kept in a portable Styrofoam box with ice packs (at approximately $0-4^{0} \mathrm{C}$ ) and processed within 6 hours for long term storage at $-70^{\circ} \mathrm{C}$. All participants also filled out a biospecimen collection form at the time of sample collection, which included the date and time of sample collection, time of last meal, and use of any medications during the previous week.

Controls of our previous reported nested case-control studies were randomly selected from cohort members and individually matched to each case by age at sample collection (within 2 years), sex, time of sample collection (morning or afternoon), date of sample collection (within 1 month), and time interval since last meal (within 2 hours). Controls were free of cancer at the time of cancer diagnosis of their corresponding case. The total sample from the previous nested case-control studies consisted of 5,726 adults, including 2,799 cancer cases (537 lung, 275 pancreatic, 368 stomach, 603 colorectal, 597 breast, 120 ovarian, 160 corpus uteri, and 88 other cancers) and 
2,927 non-cancer controls. We excluded all cancer cases from this study. Among the remaining 2,927 non-cancer individuals, 2,276 women and 651 men were participants from the SWHS and the SMHS respectively.

\section{Urinary PGE-M measurement}

Urinary PGE-M (11-a-hydroxy-9,15-dioxo-2,3,4,5-tetranor-prostane-1,20-dioic acid) level was measured using a liquid chromatography/tandem mass spectrometric method as described in previous studies (2,8-13). Briefly, $0.75 \mathrm{~mL}$ urine was acidified to $\mathrm{pH} 3$ with $\mathrm{HCl}$ and endogenous $\mathrm{PGE}-\mathrm{M}$ was then converted to the $O$-methyloxime derivative by treatment with methyloxime $\mathrm{HCl}$. The methoximated PGE-M was extracted, applied to a C-18 Sep-Pak, and eluted with ethyl acetate. Liquid chromatography was conducted on a Zorbax Eclipse XDB-C18 column attached to a ThermoFinnigan Surveyor MS Pump (Thermo Finnigan). For endogenous PGE-M, the predominant product ion $\mathrm{m} / \mathrm{z} 336$ representing $\left[\mathrm{M}-\left(\mathrm{OCH}_{3}+\mathrm{H}_{2} \mathrm{O}\right)\right]^{-}$and the analogous ion, $\mathrm{m} / \mathrm{z} 339\left[\left(\mathrm{M}-\mathrm{OC}\left[{ }^{2} \mathrm{H}_{3}\right]+\mathrm{H}_{2} \mathrm{O}\right)\right]^{-}$for the deuterated internal standard, was monitored in the selected reaction monitoring (SRM) mode. Quantification of endogenous PGE-M used the ratio of the mass chromatogram peak areas of the $\mathrm{m} / \mathrm{z} 336$ and $\mathrm{m} / \mathrm{z} 339$ ions. The lower limit of detection of PGE-M was in the range of 40 pg, approximately 100 -fold below levels in normal human urine. The coefficients of variation varied from $2.8 \%$ to $10.8 \%$ across the studies for samples analyzed within batches. Urinary creatinine levels were measured using a test kit from Sigma Company. The PGE-M levels were reported as ng PGE-M/mg creatinine.

Laboratory staff was blinded to the case-control status of urine samples and the identity of quality control samples included in the studies.

\section{Outcome ascertainment}

Death information was obtained through the follow-up surveys and by linkage to the database of the Shanghai Death Registry. The underlying cause of each death was assigned according to the international classification of diseases (9th version). The end date of the observation in this analysis was set as the date of death for deceased cohort members or the date of the last follow-up or June 30, 2016 for those who were still alive, half a year ahead of the last annual linkage with the Shanghai Death Registry, whichever was earlier. Cause-specific mortality categories were grouped according to the ICD-9 codes and were classified as diabetes (ICD-9 250), diseases of circulatory system (ICD-9 401-459), and all other causes.

\section{Statistical analyses}

The distribution of urinary creatinine-adjusted PGE-M levels was skewed to the high values and thus logtransformation was used to improve the normality. We used linear regression models to evaluate changes of logtransformed PGE-M levels by selected demographic or lifestyle factors and medication use during the previous week of sample collection. Thus, the exponential of regression coefficients represents the ratio of geometric means for categorical variables as compared with the reference group or for each unit increment of a continuous variable. The selected covariates were included in the same linear models for mutual adjustment.

The hazard ratios (HR) and 95\% confidence intervals (Cl) for the association of urinary PGE-M levels and subsequent overall or cause-specific mortalities were analyzed using Cox proportional hazards models stratified by batches of urinary PGE-M assay. We used the age as the time scale with left truncation at age of sample collection. 
The proportional hazards assumption was evaluated with the Schoenfeld residuals. We used the restricted cubic spline function for urinary PGE-M levels to examine the linearity of its association with the mortalities(16). The cause-specific mortality was analyzed in the competing risks context using the cause-specific hazards functions approach(17). Potential confounders, including age at sample collection, education levels, income, use of NSAID or antibiotics one week before urinary sample collection, alcohol drinking status (ever/never), smoking pack-years, $\mathrm{BMI}$ and WHR, were included in the regression models for adjustment.

\section{Results}

Among the 2,927 participants included in this analysis, the median (range) age at urine sample collection was 59.7 (49.7-66.3) years and the median (range) of follow-up periods was 17.4 (14.3-18.6) years. A total of 361 (12.3\%) participants died during the follow-up [36 (1.2\%) of diabetes, $211(7.2 \%)$ of diseases of circulatory system, and 114 (3.9\%) of other causes]. Both diabetes and cardiovascular diseases are metabolic disorders and were thus were grouped together as cardiometabolic diseases in the subsequent analysis of cause-specific mortality.

Table 1 presents the frequencies of selected demographic and lifestyle factors by gender and the association of these factors with log-transformed PGE-M levels. Of note, individuals with education less than middle school, without use of NSAID during the week preceded the urine collection, with smoking pack-years $>40$ had significantly increased PGE-M levels as compared with the respective reference groups, so did the individuals with older age and higher waist-hip ratio.

A significant linear association of urinary PGE-M levels with risk of all-cause mortality and deaths from cardiometabolic diseases was shown in Figure 1. The statistical tests for non-linearity of the association based on the restricted cubic spline function were not significant with $P=0.9418$ for all-cause mortality and $P=0.3737$ for deaths from cardiometabolic diseases. Table 2 presents the adjusted association of death with categorized and continuous (for each standard deviation increment) PGE-M levels. As compared with the first quintile of PGE-M, higher levels of urinary PGE-M were associated with higher risk of deaths with highly significant linear trend $(\mathrm{HR}=1.19,95 \% \mathrm{Cl}: 1.07,1.33$. $P=0.001$ for all-cause mortality and $\mathrm{HR}=1.27,95 \% \mathrm{Cl}: 1.11,1.44, P=0.0003$ for death from cardiometabolic diseases). Urinary PGE-M levels were not significantly associated with deaths from the other causes.

As shown in Table 3 and Figure 2, the adjusted associations between urinary PGE-M levels and all-cause mortality were significantly stronger among participants who had younger age $(<60)$ at urine sample collection than among those who were older ( $>=60)$ with $\mathrm{HR}=2.24,95 \% \mathrm{Cl}: 1.56,3.23$ vs $\mathrm{HR}=1.13,95 \% \mathrm{Cl}: 1.00,1.26, P$ for heterogeneity test $=0.0014$. A similar pattern was observed for the associations for deaths from cardiometabolic diseases with $\mathrm{HR}=2.45,95 \% \mathrm{Cl}: 1.47,4.07$ vs $\mathrm{HR}=1.21,95 \% \mathrm{Cl}: 1.06,1.38, P$ for heterogeneity test $=0.007$. We also observed marginally significantly stronger associations ( $P$ for heterogeneity test $=0.054$ for all-cause mortality and $p$ for heterogeneity test $=0.116$ for deaths from cardiometabolic diseases) among participants who had higher education (>=high school) than among those who had less than high school education.

The associations between urinary PGE-M levels and death were generally consistent across gender, NSAID use, smoking status, levels of waist-hip ratio, and different time intervals during the follow-up (Table 3).

Figure 3 shows the cumulative overall mortality at 25\% (Q1) and 75\% (Q3) percentiles of urinary PGE-M levels by age at urine collection ( $<60$ vs $>=60$ ) with adjustment for the covariables. Consistent with the results shown in 
Table 3 and Figure 2, higher urinary PGE-M levels were associated with higher cumulative overall mortality, which was more evident among participants who were younger than 60 at urine collection. Similar patterns were observed when plotting curves for the cumulative mortality from cardiometabolic diseases.

\section{Discussion}

In this prospective study, we found that high concentrations of urinary PGE-M were positively related with low education, heaving smoking, old age at urine sample collection, and abdominal obesity as measured with waist-hip ratio. After adjustment for these covariates, we observed that higher concentrations of urinary PGE-M were still associated with a significantly increased all-cause mortality and particularly diabetes and CVD mortality. These positive association was consistent across different time intervals since study enrollment and were stronger among participants who were younger than 60 at urine collection or marginally significantly higher among those who had higher education.

Previous studies reported that low socioeconomic status(18), smoking $(19,20)$, older age $(21,22)$ and obesity $(23,24)$ were positively associated with chronic inflammation. The chemical constituents of tobacco smoke could induce cyclooxygenase-2 (COX-2) and $\mathrm{PGE}_{2}$ synthesis (25). Aging and obesity are characterized by chronic inflammation. The inflammatory status becomes pervasive over time owing to the exposure to a variety of stressors in older people(21). Obesity increases the release of pro-inflammatory cytokines and induces multiple components of an inflammatory state (26). It is well established that biomarkers of inflammation are robust predictors of obesity and morbidity (chronic diseases) / mortality in older people(26-28). Low socioeconomic status could affect inflammation due to chronic stress, obesity, unhealthy diet, and physical inactivity in people experiencing socioeconomic adversity(18).

As an inflammatory marker (1), PGE-M was observed to be positively associated mortality, mainly from cardiometabolic diseases in this study. It is well documented that inflammation plays an important role in the etiology of these diseases $(18,29,30)$. A recent study revealed that COX-2/PGE 2 signaling was involved in the regulation of IL-1 $\beta$ auto-stimulation, thus forming an IL-1 $\beta / C O X-2 / \mathrm{PGE}_{2}$ pathway loop, which may result in the high inflammation level and play a pivotal role in the pathogenesis of type 2 diabetes(31). $\mathrm{PGE}_{2}$ plays a key role in the pathogenesis of cardiovascular diseases. It was reported (29) that a deficiency of $\mathrm{PGE}_{2}$ synthase-1 reduced plaque burden in fat-diet low-density lipoprotein receptor knockout mice, and $\mathrm{PGE}_{2}$ synthase- 1 knockout mice showed impaired left ventricular contraction after acute myocardial infarction. These findings indicate that $\mathrm{PGE}_{2} \mathrm{plays} \mathrm{a}$ pivotal role in cardiovascular inflammation.

We previously reported positive associations of PGE-M with multiple cancers including colorectal cancers(8), gastric cancer(12), breast cancer(10), and pancreatic cancer(11). Other studies also reported similar findings (3234). We did not include cancer patients in the current analysis, as their inclusion might introduce bias in the overall mortality analysis.

We observed consistent PGE-M-death association between early and late periods of the follow-up, which demonstrates the importance of chronic inflammation on premature mortality, emphasizing on controlling for chronic inflammation throughout the life span.

We found that the positive associations were weaker among participants who were older than 60 at urine collection or perhaps among those who had low education. Older people become more vulnerable a wide range of 
diseases due to declines in biological function and the accretion of cumulative risk factors(35). Similarly, the increased health burden due to a constellation of biologic, behavioral, and psychosocial risk factors that are more prevalent in people with low socioeconomic status(36). These factors hence should attenuate the influence of PGE-M on mortality.

Our study's strengths include its prospective design and adjustment for multiple potential confounders, which minimized the selection bias and confounding. In addition, our study has relatively large sample size and long period of follow-up time. To our knowledge, it comprises the first prospective study to directly evaluate the association of PGE-M with mortality with decent statistical power. There may be a concern that the results from this study were based on a single measurement of a spot urine sample of PGE-M. Ideally, the study hypothesis would be bolstered if multiple measurements of urine samples collected at several different time points were available. Therefore, the association of PGE-M and mortality may have been underestimated due to the less than optimal exposure measurement.

\section{Conclusion}

We found in this study that multiple modifiable factors such as low education, heaving smoking, and abdominal obesity were associated with increased inflammatory responses, as measured with urinary PGE-M concentrations. Higher concentration of urinary PGE-M was associated with increased mortality. We believe that improving lifestyles, e.g., stopping smoking and controlling body weight, would help decrease premature mortality through the pathway of decreasing over-production of $P G E_{2}$.

\section{Declarations}

Acknowledgements: The authors would like to thank Dr. Yong-Bing Xiang, Dr Hong-Lan Li, and Dr Yu-Ting Tan, of the State Key Laboratory of Oncogene and Related Genes \& Department of Epidemiology, Shanghai Cancer Institute, China, for their help in the data collection.

Author Contributions: WW. and WZ designed the research; GY and QC collected the data;

WW, XOS, and WZ performed data analysis; WW wrote the manuscript; All authors have read and approved the final manuscript.

Funding: This work was supported by National Institutes of Health (UM1CA182910, UM1CA173640, P50CA90949, and R01CA122364). Part of urine sample preparation was conducted at the Survey and Biospecimen Shared Resources, which is supported in part by the Vanderbilt-Ingram Cancer Center (P30CA68485).

Availability of data and materials: The datasets generated and/or analyzed during the current study are not publicly available out of protection for individual participants privacy, but de-identified data may be available from the corresponding author on reasonable request.

Ethics approval and consent to participate: The protocol was approved by the Committee of Ethical Research from the Vanderbilt University, and written informed consent was obtained from all participants.

Consent for publication: Not applicable.

Competing interests: The authors declare that they have no competing interests. 


\section{References}

1. Ricciotti E, FitzGerald GA. Prostaglandins and inflammation. Arterioscler Thromb Vasc Biol. 2011 May;31(5):986-1000.

2. Murphey LJ, Williams MK, Sanchez SC, Byrne LM, Csiki I, Oates JA, et al. Quantification of the major urinary metabolite of PGE2 by a liquid chromatographic/mass spectrometric assay: determination of cyclooxygenase-specific PGE2 synthesis in healthy humans and those with lung cancer. Anal Biochem. 2004 Nov 15;334(2):266-75.

3. Wang D, DuBois RN. Urinary PGE-M: a promising cancer biomarker. Cancer Prev Res. 2013 Jun;6(6):507-10.

4. Couzin-Frankel J. Inflammation bares a dark side. Science. 2010 Dec 17;330(6011):1621.

5. Bennett JM, Reeves G, Billman GE, Sturmberg JP. Inflammation-Nature's Way to Efficiently Respond to All Types of Challenges: Implications for Understanding and Managing "the Epidemic" of Chronic Diseases. Front Med. 2018;5:316.

6. Furman D, Campisi J, Verdin E, Carrera-Bastos P, Targ S, Franceschi C, et al. Chronic inflammation in the etiology of disease across the life span. Nat Med. 2019 Dec;25(12):1822-32.

7. Global, regional, and national age-sex-specific mortality for 282 causes of death in 195 countries and territories, 1980-2017: a systematic analysis for the Global Burden of Disease Study 2017. Lancet. 2018 Nov 10;392(10159):1736-88.

8. Cai Q, Gao Y-T, Chow W-H, Shu X-O, Yang G, Ji B-T, et al. Prospective study of urinary prostaglandin E2 metabolite and colorectal cancer risk. J Clin Oncol. 2006 Nov 1;24(31):5010-6.

9. Dong LM, Shu X-O, Gao Y-T, Milne G, Ji B-T, Yang G, et al. Urinary prostaglandin E2 metabolite and gastric cancer risk in the Shanghai women's health study. Cancer Epidemiol Biomark Prev. 2009 Nov;18(11):3075-8.

10. Cui Y, Shu X-O, Gao Y-T, Cai Q, Ji B-T, Li H-L, et al. Urinary prostaglandin E2 metabolite and breast cancer risk. Cancer Epidemiol Biomark Prev. 2014 Dec;23(12):2866-73.

11. Cui Y, Shu X-O, Li H-L, Yang G, Wen W, Gao Y-T, et al. Prospective study of urinary prostaglandin E2 metabolite and pancreatic cancer risk. Int J Cancer. 2017 Dec 15;141(12):2423-9.

12. Wang T, Cai H, Zheng W, Michel A, Pawlita M, Milne G, et al. A Prospective Study of Urinary Prostaglandin E2 Metabolite, Helicobacter pylori Antibodies, and Gastric Cancer Risk. Clin Infect Dis. 2017 May 15;64(10):13806.

13. Barnard ME, Beeghly-Fadiel A, Milne GL, Akam EY, Chan AT, Eliassen AH, et al. Urinary PGE-M Levels and Risk of Ovarian Cancer. Cancer Epidemiol Biomark Prev. 2019 Nov;28(11):1845-52.

14. Zheng W, Chow W-H, Yang G, Jin F, Rothman N, Blair A, et al. The Shanghai Women's Health Study: rationale, study design, and baseline characteristics. Am J Epidemiol. 2005 Dec 1;162(11):1123-31.

15. Shu X-O, Li H, Yang G, Gao J, Cai H, Takata Y, et al. Cohort Profile: The Shanghai Men's Health Study. Int J Epidemiol. 2015 Jun;44(3):810-8.

16. Harrell F. Regression Modeling Strategies: With Applications to Linear Models, Logistic and Ordinal Regression, and Survival Analysis. 2nd ed. New York; 2015.

17. Austin PC, Fine JP. Practical recommendations for reporting Fine-Gray model analyses for competing risk data. Stat Med. 2017 Nov 30;36(27):4391-400.

18. Stringhini S, Zaninotto P, Kumari M, Kivimäki M, Batty GD. Lifecourse socioeconomic status and type 2 diabetes: the role of chronic inflammation in the English Longitudinal Study of Ageing. Sci Rep. 2016 Apr 
22;6:24780.

19. Duffield-Lillico AJ, Boyle JO, Zhou XK, Ghosh A, Butala GS, Subbaramaiah K, et al. Levels of prostaglandin E metabolite and leukotriene $\mathrm{E}(4)$ are increased in the urine of smokers: evidence that celecoxib shunts arachidonic acid into the 5-lipoxygenase pathway. Cancer Prev Res. 2009 Apr;2(4):322-9.

20. Gross ND, Boyle JO, Morrow JD, Williams MK, Moskowitz CS, Subbaramaiah K, et al. Levels of prostaglandin E metabolite, the major urinary metabolite of prostaglandin E2, are increased in smokers. Clin Cancer Res. 2005 Aug 15;11(16):6087-93.

21. Franceschi C, Garagnani P, Vitale G, Capri M, Salvioli S. Inflammaging and “Garb-aging”. Trends Endocrinol Metab TEM. 2017 Mar;28(3):199-212.

22. Goldberg EL, Dixit VD. Drivers of age-related inflammation and strategies for healthspan extension. Immunol Rev. 2015 May;265(1):63-74.

23. Saltiel AR, Olefsky JM. Inflammatory mechanisms linking obesity and metabolic disease. J Clin Invest. 2017 Jan 3;127(1):1-4.

24. Yasui M, Tamura Y, Minami M, Higuchi S, Fujikawa R, Ikedo T, et al. The Prostaglandin E2 Receptor EP4 Regulates Obesity-Related Inflammation and Insulin Sensitivity. PloS One. 2015;10(8):e0136304.

25. Shin VY, Wu WKK, Ye Y-N, So WHL, Koo MWL, Liu ESL, et al. Nicotine promotes gastric tumor growth and neovascularization by activating extracellular signal-regulated kinase and cyclooxygenase-2. Carcinogenesis. 2004 Dec;25(12):2487-95.

26. Gonzalez MB, Lane M, Knight EJ, Robker RL. Inflammatory markers in human follicular fluid correlate with lipid levels and Body Mass Index. J Reprod Immunol. 2018 Nov;130:25-9.

27. Singh T, Newman AB. Inflammatory markers in population studies of aging. Ageing Res Rev. 2011 Jul;10(3):319-29.

28. Levine ME, Lu AT, Quach A, Chen BH, Assimes TL, Bandinelli S, et al. An epigenetic biomarker of aging for lifespan and healthspan. Aging. 2018 Apr 18;10(4):573-91.

29. Suzuki J, Ogawa M, Watanabe R, Takayama K, Hirata Y, Nagai R, et al. Roles of prostaglandin E2 in cardiovascular diseases. Int Heart J. 2011;52(5):266-9.

30. Sorriento D, laccarino G. Inflammation and Cardiovascular Diseases: The Most Recent Findings. Int J Mol Sci. 2019 Aug 9;20(16).

31. Wang G, Liang R, Liu T, Wang L, Zou J, Liu N, et al. Opposing effects of IL-1beta/COX-2/PGE2 pathway loop on islets in type 2 diabetes mellitus. Endocr J. 2019 Aug 29;66(8):691-9.

32. Wang D, DuBois RN. An inflammatory mediator, prostaglandin E2, in colorectal cancer. Cancer J Sudbury Mass. 2013 Dec;19(6):502-10.

33. Echizen K, Hirose O, Maeda Y, Oshima M. Inflammation in gastric cancer: Interplay of the COX-2/prostaglandin E2 and Toll-like receptor/MyD88 pathways. Cancer Sci. 2016 Apr;107(4):391-7.

34. Qi R, Wang D-T, Xing L-F, Wu Z-J. miRNA-21 promotes gastric cancer growth by adjusting prostaglandin E2. Eur Rev Med Pharmacol Sci. 2018 Apr;22(7):1929-36.

35. House JS, Lepkowski JM, Kinney AM, Mero RP, Kessler RC, Herzog AR. The social stratification of aging and health. J Health Soc Behav. 1994 Sep;35(3):213-34.

36. Schultz WM, Kelli HM, Lisko JC, Varghese T, Shen J, Sandesara P, et al. Socioeconomic Status and Cardiovascular Outcomes: Challenges and Interventions. Circulation. 2018 May 15;137(20):2166-78. 


\section{Tables}

Table 1. Frequency distributions of selected participants' characteristics and their associations with urinary PGE-M levels 


\begin{tabular}{|c|c|c|c|c|c|}
\hline & $\begin{array}{c}\text { Women } \\
(\mathrm{N}=2276)\end{array}$ & $\operatorname{Men}(\mathrm{N}=651)$ & \multicolumn{3}{|c|}{ All participants $(N=2927)$} \\
\hline Education & $\%$ & 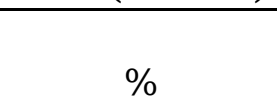 & $\%$ & $\begin{array}{l}\text { Ratio }(95 \% \\
\mathrm{CI}^{*}\end{array}$ & $\mathrm{p}$ \\
\hline $\begin{array}{r}\text { More than high } \\
\text { school }\end{array}$ & 12.2 & 26.6 & 15.4 & Reference & \\
\hline High school & 22.2 & 28.1 & 23.5 & $\begin{array}{c}1.00(0.93 \\
1.07)\end{array}$ & 0.955 \\
\hline Middle school & 32.5 & 31.0 & 32.1 & $\begin{array}{c}0.98(0.92 \\
1.05)\end{array}$ & 0.649 \\
\hline $\begin{array}{r}\text { Less than middle } \\
\text { school }\end{array}$ & 33.1 & 14.3 & 28.9 & $\begin{array}{c}1.08(1.00 \\
1.17)\end{array}$ & 0.044 \\
\hline \multicolumn{6}{|l|}{ Income } \\
\hline Low & 19.6 & 8.6 & 17.2 & Reference & \\
\hline Median & 37.1 & 47.9 & 39.5 & $\begin{array}{c}0.98(0.92, \\
1.04)\end{array}$ & 0.561 \\
\hline High & 43.3 & 43.4 & 43.4 & $\begin{array}{c}0.94(0.88 \\
1.01)\end{array}$ & 0.069 \\
\hline \multicolumn{6}{|l|}{$\begin{array}{l}\text { Regular physical } \\
\text { activity }\end{array}$} \\
\hline No & 58.3 & 46.5 & 55.7 & Reference & \\
\hline Yes & 41.7 & 53.5 & 44.3 & $\begin{array}{c}0.99(0.94, \\
1.03)\end{array}$ & 0.524 \\
\hline \multicolumn{6}{|l|}{ NSAID use ${ }^{\dagger}$} \\
\hline No & 90.3 & 86.2 & 89.4 & Reference & \\
\hline Yes & 9.7 & 13.8 & 10.6 & $\begin{array}{c}0.81(0.76, \\
0.87)\end{array}$ & $6.5 \times 10^{-9}$ \\
\hline \multicolumn{6}{|l|}{ Antibiotics use $^{\dagger}$} \\
\hline No & 93.6 & 95.1 & 93.9 & Reference & \\
\hline Yes & 6.4 & 4.9 & 6.1 & $\begin{array}{c}0.96(0.88 \\
1.05) \\
\end{array}$ & 0.378 \\
\hline \multicolumn{6}{|l|}{ Smoking pack-years $^{\ddagger}$} \\
\hline 0 & 97.0 & 43.0 & 85.0 & Reference & \\
\hline$<=20$ & 3.0 & 22.9 & 7.4 & $\begin{array}{c}1.01(0.93 \\
1.11)\end{array}$ & 0.789 \\
\hline$<=40$ & & 22.7 & 5.1 & $\begin{array}{c}1.05(0.94 \\
1.18)\end{array}$ & 0.383 \\
\hline$>40$ & & 11.4 & 2.5 & $\begin{array}{c}1.22(1.05 \\
1.42)\end{array}$ & 0.008 \\
\hline \multicolumn{6}{|l|}{$\begin{array}{l}\text { Ever had alcohol- } \\
\text { drinking }\end{array}$} \\
\hline No & 97.5 & 66.4 & 90.6 & Reference & \\
\hline Yes & 2.5 & 33.6 & 9.4 & $\begin{array}{c}1.04(0.96 \\
1.13)\end{array}$ & 0.320 \\
\hline & $\operatorname{Median}\left(\mathrm{IQR}^{\S}\right)$ & Median(IQR) & Median(IQR) & & \\
\hline $\begin{array}{l}\text { Age at sample } \\
\text { collection }\end{array}$ & $\begin{array}{c}57.7(48.6 \\
64.9)\end{array}$ & $\begin{array}{c}66.0(55.9 \\
71.1)\end{array}$ & $\begin{array}{c}59.7(49.7 \\
66.3)\end{array}$ & $\begin{array}{c}1.04(1.03 \\
1.06)\end{array}$ & $6.8 \times 10^{-9}$ \\
\hline
\end{tabular}




\begin{tabular}{|l|c|c|c|c|c|} 
Body mass index & $24.1(22.0$, & $23.8(21.8$, & $24.0(21.9$, & $1.01(0.99$, & 0.237 \\
& $26.6)$ & $25.6)$ & $26.5)$ & $1.04)$ & \\
\hline Waist-hip ratio & $\begin{array}{c}0.82(0.78, \\
0.85)\end{array}$ & $0.90(0.86,0.94)$ & $\begin{array}{c}0.83(0.79, \\
0.88)\end{array}$ & $\begin{array}{c}1.06(1.03, \\
1.09)\end{array}$ & $5.4 \times 10^{-5}$ \\
\hline
\end{tabular}

* Ratio of geometric means with mutual adjustment for all variables listed in the table. It was estimated as compared with the reference group for categorical variables, or for each 5-year increment for age at sample collection, or for each standard deviation increment for BMI and WHR.

${ }^{\dagger}$ Ever used NSAID or antibiotics one week before urinary sample collection.

‡ For women, smoking pack-years were defined as 0 or $>0$.

$\S$ IQR: Interquartile range.

Table 2. Association between urinary PGE-M levels and death

\begin{tabular}{|c|c|c|c|c|c|c|c|c|c|}
\hline & \multicolumn{3}{|c|}{ All-cause mortality } & \multicolumn{3}{|c|}{$\begin{array}{c}\text { Died of cardiometabolic } \\
\text { diseases }\end{array}$} & \multicolumn{3}{|c|}{ All other causes of death } \\
\hline $\begin{array}{l}\text { PGE-M } \\
\text { levels }\end{array}$ & $\begin{array}{l}\text { No. of } \\
\text { deaths }\end{array}$ & $\begin{array}{c}\mathrm{HR}(95 \% \\
\mathrm{CI})^{*}\end{array}$ & $\mathrm{P}$ & $\begin{array}{l}\text { No. of } \\
\text { deaths }\end{array}$ & $\begin{array}{c}\mathrm{HR}(95 \% \\
\mathrm{CI})^{*}\end{array}$ & $\mathrm{P}$ & $\begin{array}{l}\text { No. of } \\
\text { deaths }\end{array}$ & $\begin{array}{c}\mathrm{HR}(95 \% \\
\mathrm{CI})^{*}\end{array}$ & $\mathrm{P}$ \\
\hline Quintile 1 & 62 & Reference & & 42 & Reference & & 20 & Reference & \\
\hline Quintile 2 & 67 & $\begin{array}{c}1.32(0.93, \\
1.88)\end{array}$ & 0.125 & 43 & $\begin{array}{c}1.25(0.81 \\
1.93)\end{array}$ & 0.323 & 24 & $\begin{array}{c}1.45(0.79 \\
2.68)\end{array}$ & 0.231 \\
\hline Quintile 3 & 74 & $\begin{array}{c}1.36(0.96, \\
1.93)\end{array}$ & 0.083 & 45 & $\begin{array}{c}1.23(0.80 \\
1.91)\end{array}$ & 0.342 & 29 & $\begin{array}{l}1.60(0.89, \\
2.88)\end{array}$ & 0.118 \\
\hline Quintile 4 & 62 & $\begin{array}{c}1.19(0.83, \\
1.70)\end{array}$ & 0.351 & 42 & $\begin{array}{c}1.22(0.79 \\
1.89)\end{array}$ & 0.364 & 20 & $\begin{array}{l}\text { 1.11(0.59, } \\
2.09)\end{array}$ & 0.739 \\
\hline Quintile 5 & 96 & $\begin{array}{l}1.73(1.25, \\
2.40)\end{array}$ & 0.0009 & 75 & $\begin{array}{c}2.01(1.37 \\
2.95)\end{array}$ & 0.0004 & 21 & $\begin{array}{l}1.17(0.63, \\
2.18)\end{array}$ & 0.612 \\
\hline Continuous & 361 & $\begin{array}{c}1.19(1.07, \\
1.33)\end{array}$ & 0.001 & 247 & $\begin{array}{c}1.27(1.11 \\
1.44)\end{array}$ & 0.0003 & 114 & $\begin{array}{c}1.03(0.85 \\
1.26)\end{array}$ & 0.745 \\
\hline
\end{tabular}

${ }^{*}$ HRs and 95 CIs for continuous urinary PGE-M were estimated for the increment by one standard deviation, with adjustment for covariates in table 1. For cause-specific death, HRs and 95\% CIs were derived from the cause-specific hazard models to account for competing risks from other causes.

Table 3. Association between urinary PGE-M levels and death, stratified by selected covariables 


\begin{tabular}{|c|c|c|c|c|c|c|}
\hline & \multicolumn{3}{|c|}{ All-cause mortality } & \multicolumn{3}{|c|}{ Died of cardiometabolic diseases } \\
\hline & $\begin{array}{l}\text { No. of } \\
\text { deaths }\end{array}$ & HR $(95 \% \mathrm{CI})^{*}$ & $\mathrm{P}$ & $\begin{array}{l}\text { No. of } \\
\text { deaths }\end{array}$ & HR $(95 \% \mathrm{CI})^{*}$ & $\mathrm{P}$ \\
\hline \multicolumn{7}{|l|}{ Gender } \\
\hline Women & 253 & $\begin{array}{c}1.15(1.01, \\
1.31)\end{array}$ & 0.035 & 173 & $\begin{array}{c}1.25(1.06, \\
1.46)\end{array}$ & 0.007 \\
\hline Men & 108 & $\begin{array}{c}1.21(0.98, \\
1.49)\end{array}$ & 0.076 & 74 & $\begin{array}{c}1.32(1.07 \\
1.63)\end{array}$ & 0.010 \\
\hline P for interaction & & & 0.690 & & & 0.679 \\
\hline \multicolumn{7}{|l|}{ Education levels } \\
\hline$<$ High school & 270 & $1.10(0.97,1.25)$ & 0.137 & 183 & $\begin{array}{c}1.18(1.02, \\
1.37) \\
\end{array}$ & 0.026 \\
\hline$>=$ High school & 91 & $1.42(1.13,1.79$ & 0.0026 & 64 & $\begin{array}{l}1.52(1.15, \\
2.00)\end{array}$ & 0.003 \\
\hline $\mathrm{P}$ for interaction & & & 0.054 & & & 0.116 \\
\hline \multicolumn{7}{|l|}{ NSAID use } \\
\hline No & 321 & $1.21(1.08,1.36)$ & 0.00093 & 221 & $\begin{array}{c}1.28(1.12, \\
1.47)\end{array}$ & 0.0003 \\
\hline Yes & 40 & $1.16(0.76,1.78)$ & 0.4777 & 26 & $\begin{array}{c}1.12(0.74, \\
1.71)\end{array}$ & 0.585 \\
\hline $\mathrm{P}$ for interaction & & & 0.869 & & & 0.557 \\
\hline \multicolumn{7}{|l|}{ Smoking status } \\
\hline Never smoked & 291 & $1.20(1.06,1.35)$ & 0.0031 & 201 & $\begin{array}{c}1.28(1.11 \\
1.49)\end{array}$ & 0.001 \\
\hline Ever smoked & 70 & $1.19(0.91,1.56)$ & 0.198 & 46 & $\begin{array}{c}1.27(0.97 \\
1.68)\end{array}$ & 0.084 \\
\hline $\mathrm{P}$ for interaction & & & 0.908 & & & 0.963 \\
\hline \multicolumn{7}{|l|}{$\begin{array}{l}\text { Age at sample } \\
\text { collection }\end{array}$} \\
\hline$<60$ & 35 & $2.24(1.56,3.23)$ & $1.0 \mathrm{e}-5$ & 20 & $\begin{array}{c}2.45(1.47 \\
4.07)\end{array}$ & 0.0006 \\
\hline$>=60$ & 326 & $1.13(1.00,1.26)$ & 0.041 & 227 & $\begin{array}{c}1.21(1.06, \\
1.38)\end{array}$ & 0.006 \\
\hline P for interaction & & & 0.0014 & & & 0.007 \\
\hline \multicolumn{7}{|l|}{ WHR values } \\
\hline$<=0.82$ (median) & 111 & $1.14(0.91,1.42)$ & 0.261 & 77 & $\begin{array}{c}1.25(0.97 \\
1.62)\end{array}$ & 0.091 \\
\hline$>0.82$ (median) & 250 & $1.20(1.06,1.36)$ & 0.0048 & 170 & $\begin{array}{c}1.27(1.10, \\
1.48)\end{array}$ & 0.001 \\
\hline $\mathrm{P}$ for interaction & & & 0.547 & & & 0.901 \\
\hline \multicolumn{7}{|l|}{ Follow-up time } \\
\hline $\begin{array}{l}\text { During the first 5- } \\
\text { year }\end{array}$ & 47 & $1.18(0.89,1.57)$ & 0.244 & 31 & $\begin{array}{c}1.34(0.96, \\
1.87)\end{array}$ & 0.091 \\
\hline $\begin{array}{l}\text { Between 5-10 } \\
\text { years }\end{array}$ & 98 & $1.17(0.97,1.43)$ & 0.108 & 61 & $\begin{array}{c}1.27(1.00 \\
1.61)\end{array}$ & 0.053 \\
\hline Over 10 years & 216 & $1.21(1.05,1.39)$ & 0.009 & 155 & $\begin{array}{c}1.25(1.06, \\
1.48)\end{array}$ & 0.007 \\
\hline P for interaction & & & 0.971 & & & 0.945 \\
\hline
\end{tabular}

${ }^{*}$ HRs and 95 CIs for continuous urinary PGE-M were estimated for the increment by one standard deviation, with adjustment for covariates in table 1. 


\section{Figures}
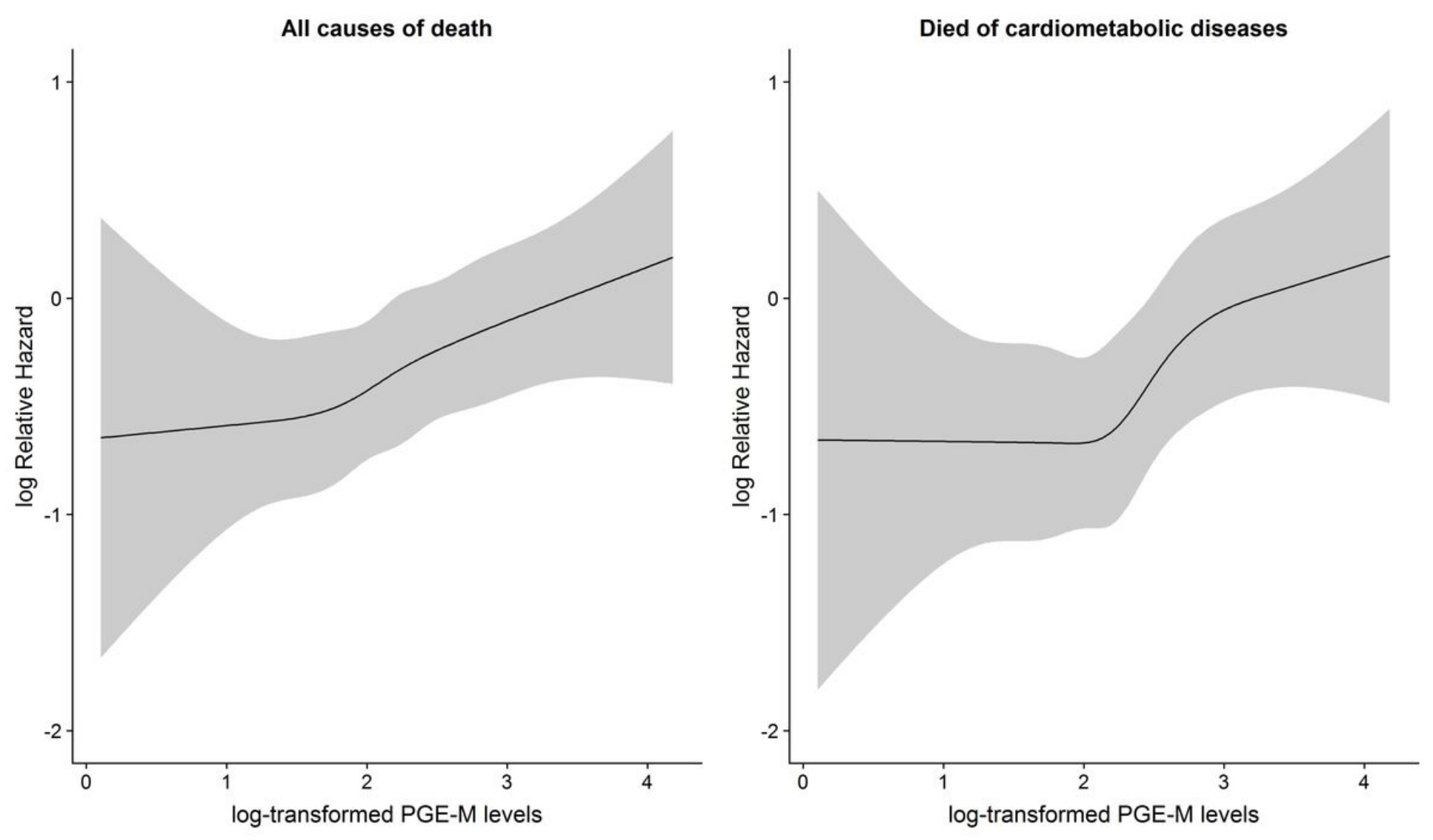

\section{Figure 1}

Associations of urinary PGE-M levels with all-cause mortality (left) and death from cardiometabolic diseases (right) using the restrict cubic spline function to account for non-linearity. 

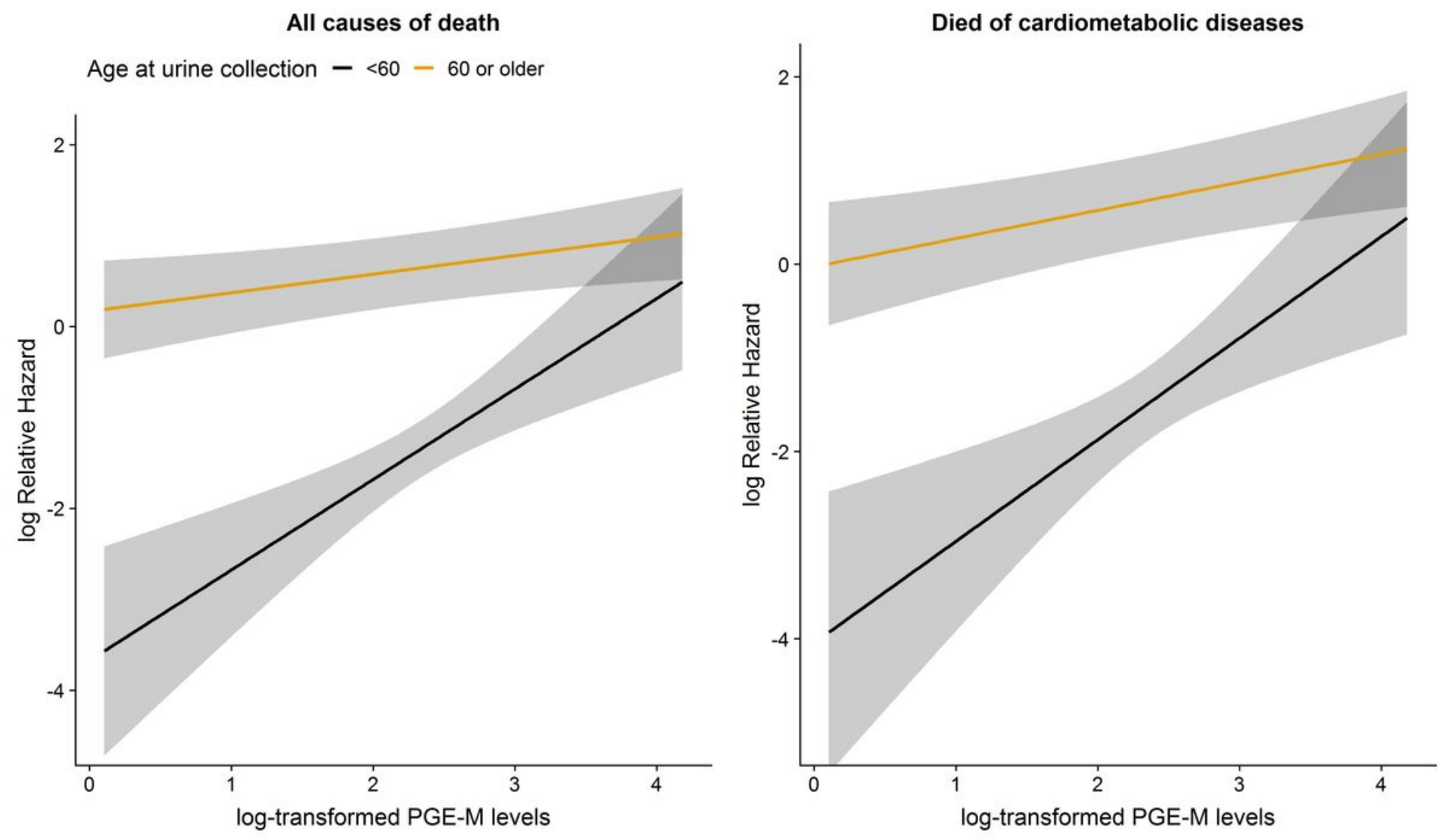

Figure 2

Linear associations of urinary PGE-M levels with all-cause mortality (left) and death from cardiometabolic diseases (right) by age at urine collection (<60 vs >=60 years). 


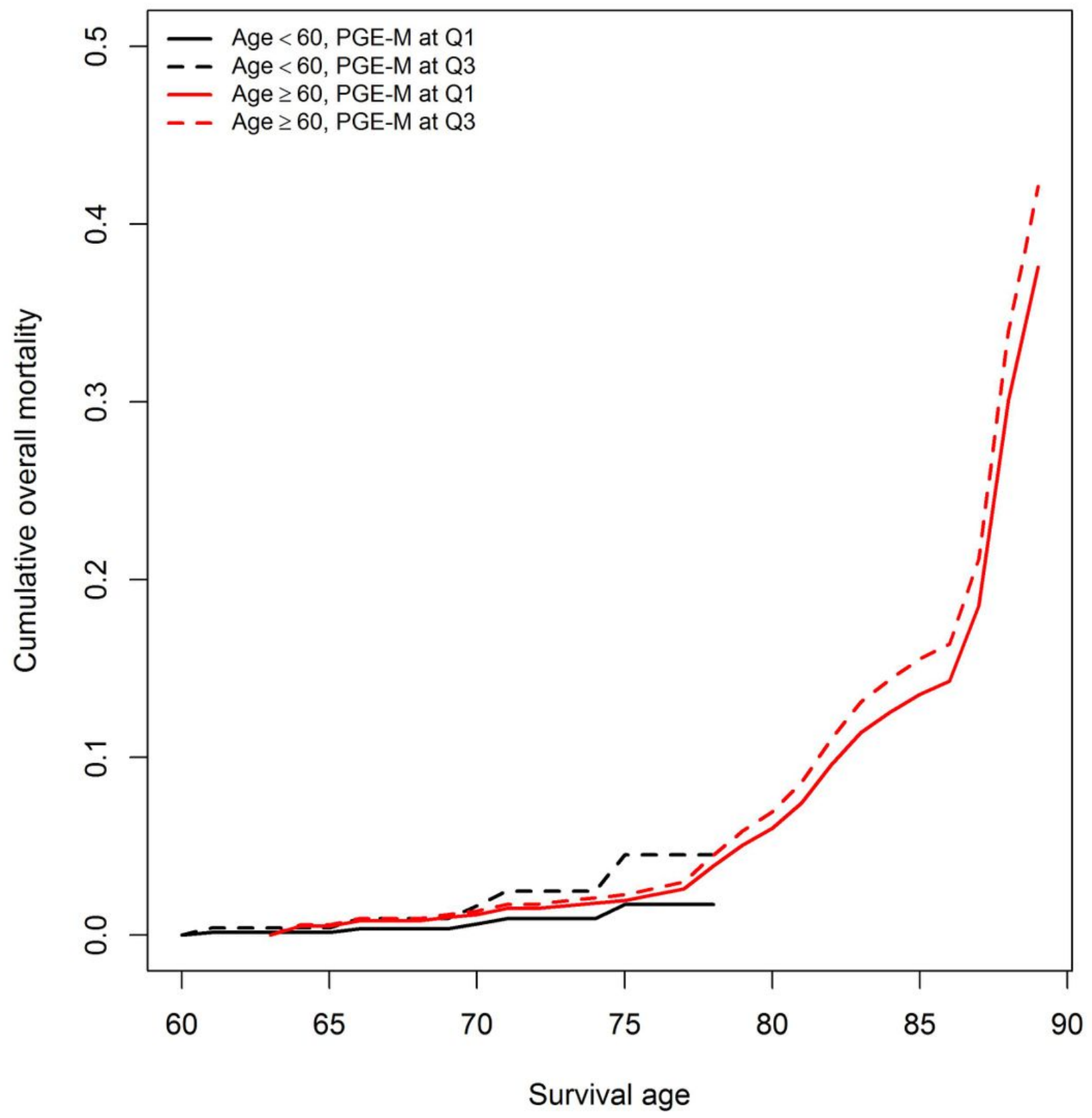

Figure 3

Cumulative mortality associated with urinary PGE-M levels [the first quartile (Q1) vs the third quartile (Q3)] by age at urine collection (<60 vs >=60 years). 